\title{
Renal dysplasia in nephrectomy specimens from adolescents and adults
}

\author{
C. FISHER AND J. F. SMITH
}

From the Department of Morbid Anatomy, University College Hospital Medical School, London WCI

SYNOPSIS In a review of 156 total or partial nephrectomy specimens from patients over the age of 12 years, renal dysplasia was found 14 times. The cases were divided initially into five groups on the basis of the predominant pathological changes, namely (1) dysplasia (14 cases), (2) chronic pyelonephritis (31 cases), (3) calculous inflammation (58 cases), (4) hydronephrosis (35 cases), and (5) miscellaneous (18 cases). The diagnosis of dysplasia was made on gross and microscopic criteria and included 12 of segmental dysplasia, one of total dysplasia, and one multicystic dysplastic kidney. The principal differential diagnosis is from the irregularly scarred chronic pyelonephritic kidney. The criteria for the separation of the two are emphasized and, in particular, the distinction from those pyelonephritic kidneys with aglomerular scars. A high incidence of anomalies of drainage was found in association with dysplasia, but such were not always present. It was not thought that intrarenal reflux in infancy was an aetiological factor. Six of the cases presented with urinary infection, but only two had hypertension. It was thought that acquired glomerular damage was more important in the aetiology of hypertension than segmental glomerular agenesis.

In this paper we record the pathological and clinical features of renal dysplasia as seen in 14 cases among 156 total or partial nephrectomy specimens examined over a 13-year period. We use the term dysplasia to indicate a disordered development of the kidney in which embryonic nephronic structures are found microscopically in postnatal life (Bernstein, 1968; Ericcson and Ivemark, 1958) usually with malformation of gross architecture. It is a well recognized lesion in children when it is often associated with congenital obstructive lesions in the lower urinary tract (Risdon, 1971) and may result in early presentation and death if severe and bilateral (Rubenstein, Meyer, and Bernstein, 1961). Its significance in unilateral cases in adolescence and adult life is less appreciated as it is often misdiagnosed as chronic pyelonephritis.

\section{Materials and Methods}

The specimens were obtained at operation from patients between 12 and 81 years and were consecutive between 1961 and 1973 except for renal tumours which were excluded. After gross examination and measurement $5 \mu$ paraffin sections of formalin fixed

Received for publication 29 April 1975. material were prepared and stained by a variety of methods. In a few cases serial sections were cut through scars.

DIAGNOSITC CRITERIA AND CLASSIFICATIONS Each case was placed in one of five groups, as described below and set out in table I on the basis of the predominant pathological change although many cases had more than one of these. The nakedeye features were used as an aid to diagnosis, but dysplasia was not diagnosed unless histological criteria were satisfied.

\section{Group 1 Dysplasia}

This always involved the medulla and usually the cortex. The presence of dysplastic collecting ducts or tubules in a loose mesenchyme in the medulla (fig 1) was the most common and consistent histological feature. The epithelium of the ducts was columnar and sometimes ciliated (fig 2) and that of the ductules cubical. A condensation of the mesenchyme as collars about the ducts (figs 1 and 2 ) was often a striking feature. In such collars smooth muscle cells with fibrils were present but much less abundant than in the tissue between tubules where they were conspicuous in PTAH preparations. The structure of the mesenchyme was different from the more dense 


\begin{tabular}{|c|c|c|c|c|c|c|c|c|c|}
\hline \multirow[t]{2}{*}{ Group } & \multirow{2}{*}{$\begin{array}{l}\text { Total } \\
\text { (age } \\
\text { in yr) }\end{array}$} & \multicolumn{2}{|c|}{ Sex } & \multicolumn{2}{|c|}{ Nephrectomy } & \multirow{2}{*}{$\begin{array}{l}\text { Hyper- } \\
\text { tension }\end{array}$} & \multirow{2}{*}{$\begin{array}{l}\text { Infec- } \\
\text { tion }\end{array}$} & \multirow[t]{2}{*}{ Pain } & \multirow{2}{*}{$\begin{array}{l}\text { Associated Anomalies } \\
\text { where present }\end{array}$} \\
\hline & & $\boldsymbol{M}$ & $F$ & Total & Partial & & & & \\
\hline 1 Dysplasia & $\begin{array}{l}14 \\
(13-63)\end{array}$ & 8 & 6 & 12 & 2 & 2 & 6 & 5 & $\begin{array}{l}\text { Triplex kidney (1) } \\
\text { Duplex kidney (2) } \\
\text { PUO (2) } \\
\text { VUR (4) } \\
\text { Hydroureter (1) }\end{array}$ \\
\hline $\begin{array}{l}2 \text { Chronic pyelonephritis } \\
\text { All cases }\end{array}$ & $\begin{array}{c}31 \\
(12-79)\end{array}$ & 9 & 22 & 26 & 5 & 16 & 16 & 9 & $\begin{array}{l}\text { PUO (3) } \\
\text { VUR (7) }\end{array}$ \\
\hline Aglomerular scars & $\begin{array}{c}9 \\
(24-61)\end{array}$ & 4 & 5 & 8 & 1 & 4 & 4 & 1 & $\begin{array}{l}\text { PUO (1; } \\
\text { VUR (2) } \\
\text { Bladder carcinoma (1) } \\
\text { Bilharzia (1) } \\
\text { Nil (4) }\end{array}$ \\
\hline 3 Calculous inflammation & $\begin{array}{l}58 \\
(24-74)\end{array}$ & 23 & 35 & 29 & 29 & 11 & 32 & 35 & Hypercalcaemia (4) \\
\hline $\begin{array}{l}\square \text { Diffuse } \\
\square \text { Focal-cortical } \\
\square \text { Focal-medullary } \\
\square \text { Pyelitis }\end{array}$ & $\begin{array}{l}11 \\
11 \\
26 \\
10\end{array}$ & $\begin{array}{l}3 \\
8 \\
9 \\
3\end{array}$ & $\begin{array}{r}8 \\
3 \\
17 \\
7\end{array}$ & $\begin{array}{r}7 \\
5 \\
14 \\
3\end{array}$ & $\begin{array}{r}4 \\
6 \\
12 \\
7\end{array}$ & $\begin{array}{l}3 \\
1 \\
5 \\
2\end{array}$ & $\begin{array}{r}8 \\
0 \\
18 \\
6\end{array}$ & $\begin{array}{r}5 \\
5 \\
15 \\
10\end{array}$ & $\begin{array}{l}\text { None specific } \\
\text { Hypercalciuria (6) } \\
\text { Oxaluria (2) } \\
\text { Cystinuria (2) } \\
\text { VUR (1) } \\
\text { Duplex kidney (1) }\end{array}$ \\
\hline 4 Hydronephrosis & $\begin{array}{l}35 \\
(15-81)\end{array}$ & 20 & 15 & 35 & 0 & s & 12 & 18 & $\begin{array}{l}\text { PUO (20) } \\
\text { Ureteric fibrosis (2) } \\
\text { Ureteric valve (1) } \\
\text { VUR (2) } \\
\text { Bladder carcinoma (4) } \\
\text { Other (6) }\end{array}$ \\
\hline 5 Miscellaneous & 18 & 8 & 10 & 18 & 0 & 7 & 6 & 11 & \\
\hline$\square$ Tuberculosis & 6 & 4 & 2 & 6 & 0 & 1 & - & 4 & \\
\hline$\square$ Renal artery stenosis & 6 & 3 & 3 & 6 & 0 & 4 & 2 & 1 & \\
\hline$\square$ Acute suppurative inflammation & 3 & 0 & 3 & 3 & 0 & 0 & 3 & 3 & $\begin{array}{l}\text { Pyonephrosis (2) } \\
\text { Perinephric abscess (1) }\end{array}$ \\
\hline$\square$ Proliferative glomerulonephritis & 1 & 0 & 1 & 1 & $\mathbf{0}$ & 1 & 0 & 1 & \\
\hline$\square$ Multilocular cyst & 1 & 0 & 1 & 1 & $\mathbf{0}$ & $\mathbf{0}$ & 0 & 1 & \\
\hline$\square$ Polycystic kidney & 1 & 1 & $\mathbf{0}$ & 1 & 0 & 1 & 1 & 1 & \\
\hline Totals & 156 & 68 & 88 & 120 & 36 & 45 & 72 & 78 & \\
\hline
\end{tabular}

Table I All cases

VUR $=$ vesico-ureteric reflux $;$ PUO = pelvi-ureteric obstruction.

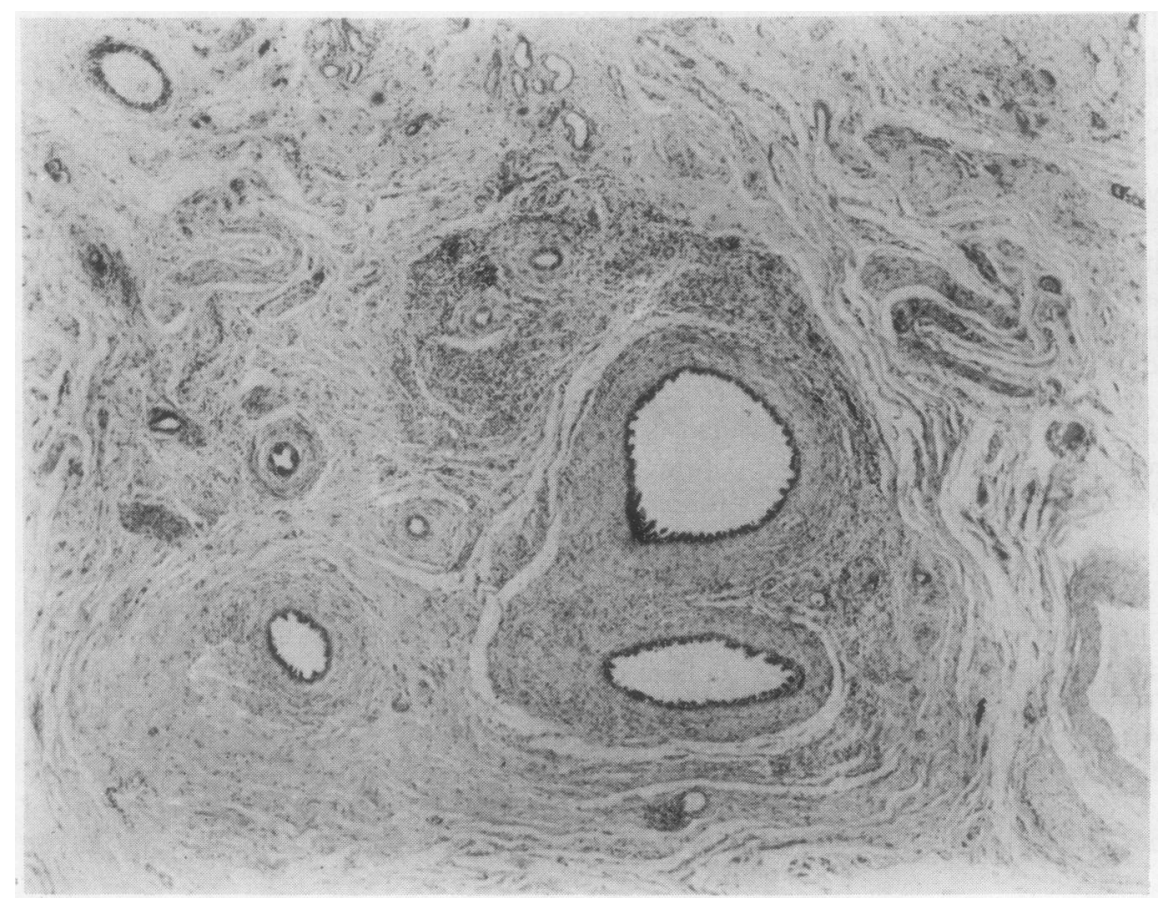

Fig 1 Dyplastic collecting ducts surrounded by collars of fibromuscular tissue and set in a loose mesenchyme. Case 6. Haematoxylin and $e \sin \times 90$. 


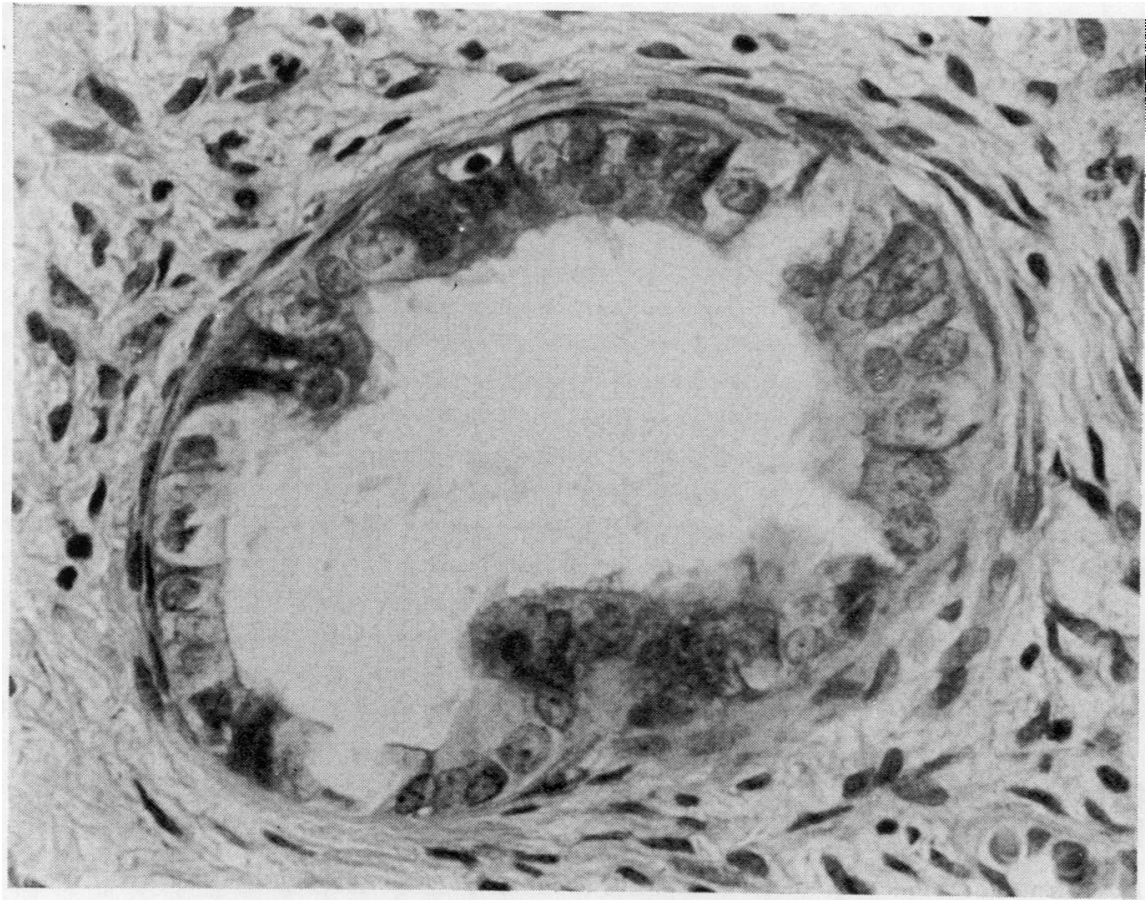

Fig 2 Columnar ciliated epithelium of dysplastic collecting ducts. Case 10.

$H$ and $E \times 360$.

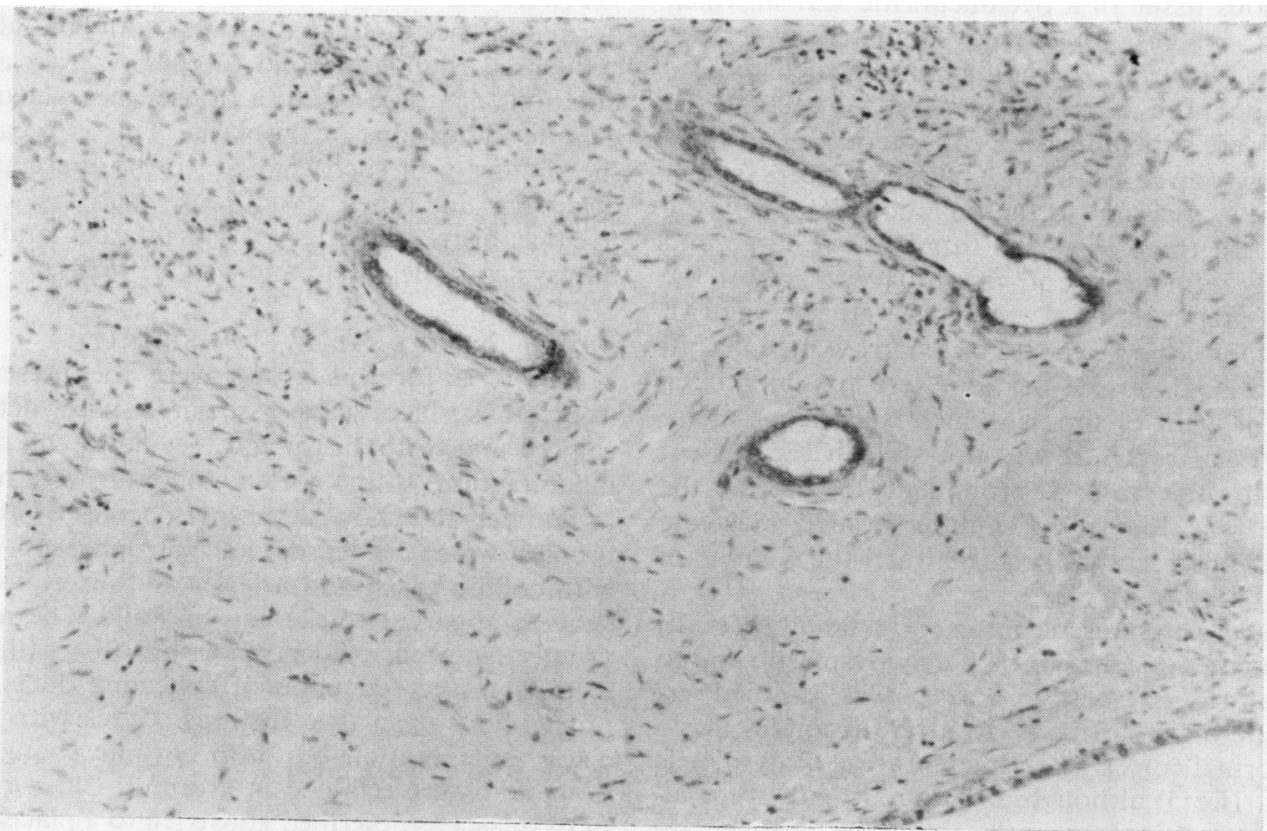
Fig 3 Regenerative flattened epithelium of ducts in dense fibrous tissue in chronic pyelonephritis.
$H$ and $E \times 85$. 


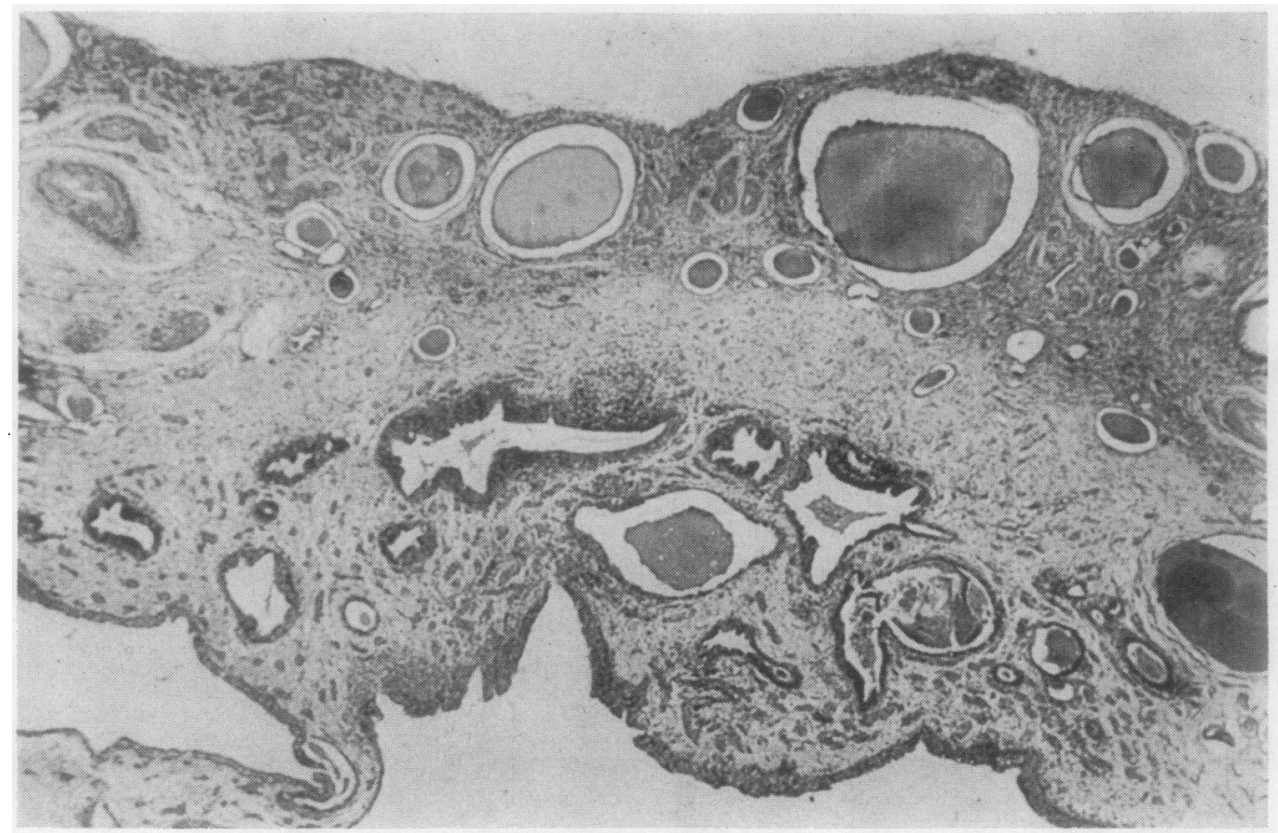

Fig 4 Dysplastic cortex and medulla with delta-like arrangement of tubules in medulla. Case 13. $H$ and $E \times 35$.

collagenous tissue of a pyelonephritic scar in which scattered tubules sometimes simulated dysplastic elements. However, the epithelium of such tubules was of the moie flattened regenerative type and the tubules were surrounded by collagen (fig 3 ).

On low-power examination two features sometimes drew attention to the possibility of dysplastic medulla. In three cases the tubules were large and obviously tributaries of the adjacent calyx - the delta configuration of Marshall (1953) (fig 4). Furthermore, they were set in a narrow medulla. In five cases foci of calcification were present in the lumina or walls of tubules which were again sparse (fig 5). Fetal cartilage was not seen in the present series. In one case a prominent feature in the medulla was islands of undifferentiated blastema (fig 6) similar to that seen between the lobules of the fetal kidney.

Changes were present in the cortex in all cases. In many, these appeared to be partly dysplastic and in the majority dysplastic cortex was drained by dysplastic medulla (fig 4). In a few examples, however, normal cortex lay over some areas of dysplastic medulla (fig 5) although abnormal islands were always present in some segments. The cortical appearances were often complicated by the effects of abnormal drainage of ischaemia and of infection.
We were unwilling to use the appearance of abnormal glomeruli, dilated tubules with colloid casts, condensed islands of solid tubules or even a combination of these with a loose mesenchyme as definite indications of dysplasia. This is because of the similarity of such changes to those accepted as occurring in other conditions such as chronic pyelonephritis, the edge of old infarcts, and renal biopsy scars (Bernstein and Meyer, 1961).

\section{GROUP 2 CHRONIC PYELONEPHRITIS}

The criteria for this group were the presence of irregular surface scars associated with deformed calyces and with histological evidence of chronic inflammation. In the cortex glomeruli were reduced in number and showed varying degrees of atrophy, tubules were condensed and atrophic or dilated with colloid casts, and arteries and arterioles often showed apparent thickening of walls. The medulla usually showed evidence of fibrosis with some distortion and reduction of collecting ducts (fig 3) but without dysplastic features. Cases with foci of acute inflammation but with chronic changes predominant were retained in group 2. Clear evidence of dysplasia as described above led to a placement in group 1, even if chronic pyelonephritis was present in part of the kidney. 


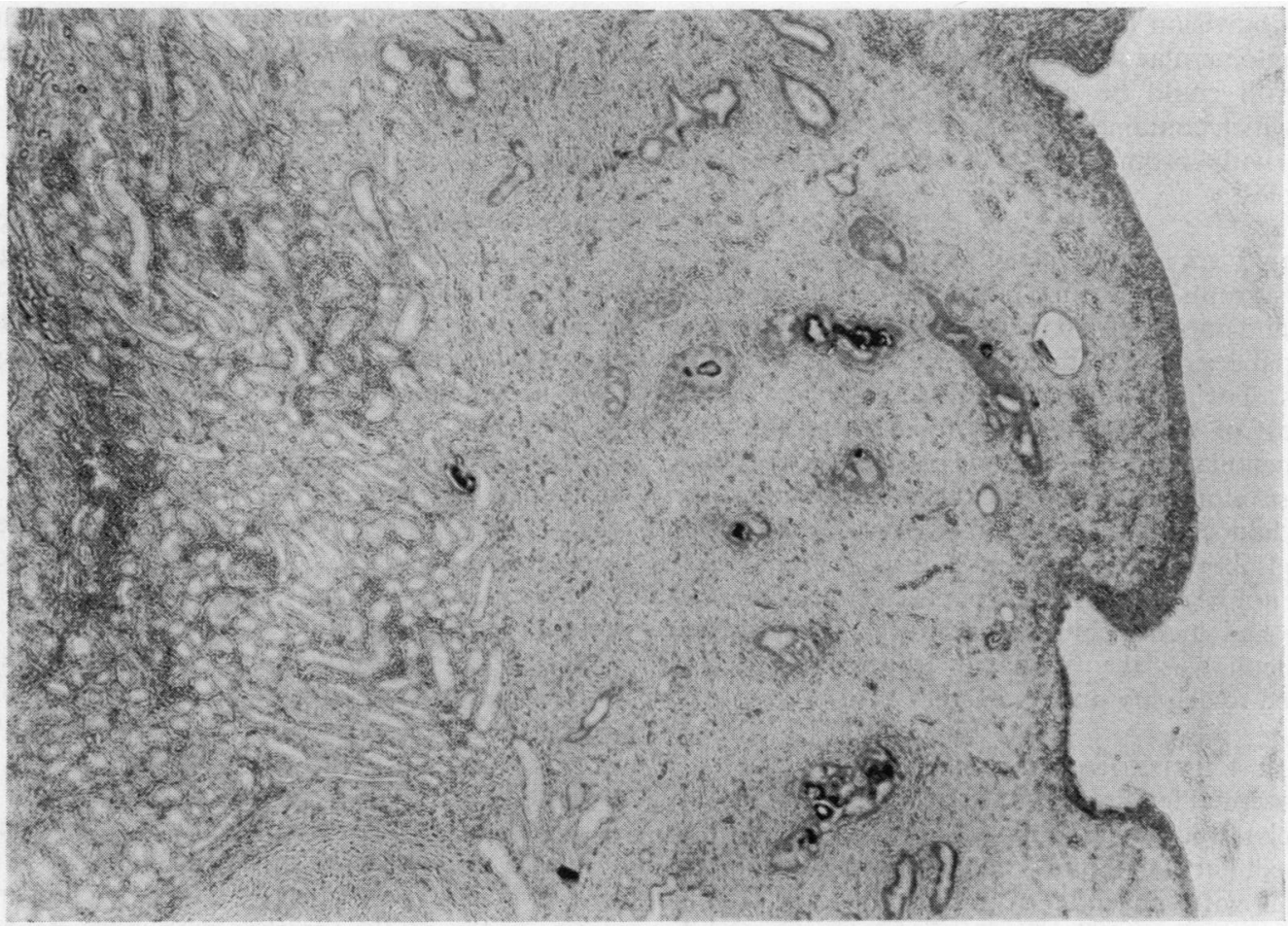

Fig 5 Focal calcification in and around sparse dysplastic ducts of medulla but the overlying cortex in this segment is normal. Case 1. H and $E \times 38$.

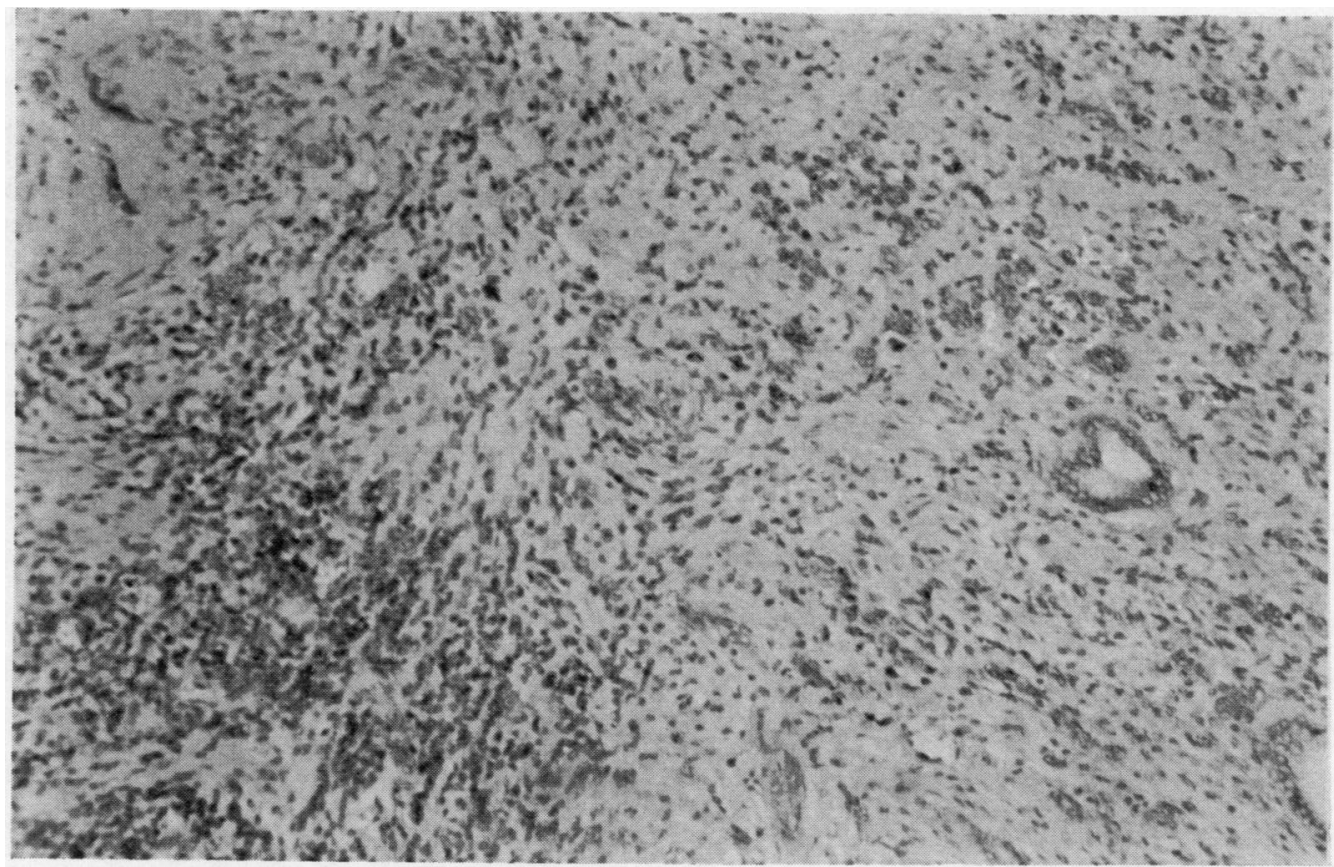

Fig 6 Undifferentiated cells of residual blastema on left, primitive ductules in loose mesenchyme on right. Case 8. $H$ and $E \times 87$. 
A subdivision of group 2 is referred to as "cases with aglomerular pyelonephritic scars'. In these, no glomeruli could be demonstrated in the cortical scars which contained atrophic or dilated tubules, or both, with prominent thick-walled arteries and arterioles.

\section{GROUP 3 CALCULOUS INFLAMMATION}

In this group of 58, one-half were partial nephrectomy and one-half total nephrectomy specimens. The essential lesion was the presence of one or more stones. The inflammatory changes involved either (i) most of the specimen, (ii) focal areas of cortex and medulla, (iii) cortex alone, or (iv) pelvicalyceal mucosa alone as set out in the tables. Thus some cases had coexisting chronic pyelonephritis as described above, some had small cortical scars which could not be distinguished from ischaemic scars, and a few had hydronephrosis. However, the presence of calculi was the dominant feature and it was decided to classify on this basis.

\section{GROUP 4 HYDRONEPHROSIS}

The essential feature was a variable degree of nakedeye pelvic and calyceal dilatation with some blunting of medullary pyramids. Histologically medullary atrophy with tangential disposition of some collecting ducts was usually present in early cases while in advanced disease there was considerable medullary and cortical atrophy. Even with extreme atrophy a few hyalinized glomeruli could be detected with both periodic acid Schiff and van Gieson stains. Inflammation was variable. Those examples in which hydronephrosis accompanied dysplasia were placed in group 1.

GROUP 5 MISCELLANEOUS

The criteria for the conditions listed here are well known and will not be described. The case of multilocular renal cysts fulfilled the criteria of Powell et al (1951).

\section{Results}

These are presented in tables I (all cases), II and III (dysplasia), and IV (aglomerular scars). The significant associated pathogenetic factors are given in the final column of table I, which also includes some clinical data. The following points about groups 1 and 2 need emphasis.

\section{GROUP 1 DYSPLASIA}

Of the 14 cases $(9 \%), 12$ were examples of segmental, one of total, dysplasia. In the segmental disease it was possible to dissect out the pelvicalyceal system, and clubbing of one or more calyces was present. In the case of total dysplasia there was generalized disorganization of parenchyma with a few scattered islands of normal tissue; in most of the others, two or more dysplastic segments were separated by areas of normally developed tissue. One large and two small cysts were present in one case of segmental dysplasia. The features of multicystic dysplasia, as described by Bernstein (1968), were present in case 9 in which cysts were present in the cortex and medulla together with hydronephrosis due to obstruction in the ureter but the gross form of the kidney was retained. In 13 cases the size was reduced, and 10 came into the category of unilateral small kidney, as defined by Gifford et al (1965).

Inflammation was present in half the cases either in or outside dysplastic areas. In some this was of sufficient severity to be considered as focal chronic pyelonephritis. This was not surprising in view of the clinical presentation with urinary tract infection in six cases, in five of which there was a structural

\begin{tabular}{|c|c|c|c|c|c|}
\hline \multirow[t]{2}{*}{ No. } & \multicolumn{5}{|c|}{ Histological Changes in Dysplastic Areas } \\
\hline & Distribution & Glomeruli & Inflammation & Calcification & Vascular Thickening \\
\hline 1 & Segmental & $\begin{array}{l}\text { A few subcapsular } \\
\text { hyalinized }\end{array}$ & _ & + & + \\
\hline 2 & Segmental & - & + & + & + \\
\hline 3 & Segmental & - & + & - & + \\
\hline 4 & Segmental & - & + & + & + \\
\hline 5 & Segmental & - & + & - & + \\
\hline \multirow[t]{2}{*}{6} & General & Island of normal & & & \\
\hline & & nephrons & - & + & - \\
\hline 7 & Segmental & - & - & - & - \\
\hline 8 & Segmental & A few abnormal & - & - & + \\
\hline 9 & Multicystic & - & - & - & + \\
\hline 10 & Segmental & - & + & - & + \\
\hline 11 & Segmental & - & - & - & + \\
\hline 12 & Segmental & - & + & + & + \\
\hline 13 & Segmental & - & - & - & + \\
\hline 14 & Segmental & - & + & - & + \\
\hline
\end{tabular}

Table II Dysplastic cases 


\begin{tabular}{|c|c|c|c|c|c|c|c|c|}
\hline No. & Age & Sex & Blood Pressure & Urinary Infection & Pain & Kidney Length $(\mathrm{cm})$ & Associated Anomalies & Inflammation \\
\hline 1 & 18 & $\mathbf{M}$ & Raised & - & - & 4 & Hydronephrosis & - \\
\hline 2 & 51 & $\mathbf{F}$ & Normal & + & - & 8 & Duplex, PUO & + \\
\hline 3 & 20 & $\mathbf{F}$ & Normal & + & - & $\begin{array}{l}4 \times 3 \times 2 \\
\text { Partial }\end{array}$ & Duplex, VUR & + \\
\hline 4 & 54 & $\mathbf{F}$ & Normal & + & - & 5 & VUR & + \\
\hline 5 & 29 & $\mathbf{M}$ & Normal & + & - & 7 & - & + \\
\hline 6 & 25 & $\mathbf{M}$ & Normal & - & + & 9 & Atretic ureter & - \\
\hline 7 & 63 & $\mathbf{M}$ & Normal & - & + & $5 \cdot 5$ & - & - \\
\hline 8 & 29 & $\mathbf{M}$ & Normal & - & + & 8 & Hydronephrosis & - \\
\hline 9 & 13 & $\mathbf{M}$ & Normal & - & + & 10 & Hydronephrosis & - \\
\hline 10 & 14 & $\mathbf{M}$ & Normal & - & + & 6 & Hydroureter & + \\
\hline 11 & 50 & $\mathbf{M}$ & Normal & - & - & 4 & - & - \\
\hline 12 & 25 & $\mathbf{F}$ & Normal & + & - & $\begin{array}{l}5 \times 3 \times 2 \\
\text { Partial }\end{array}$ & Triplex & + \\
\hline 13 & 34 & $\mathbf{F}$ & Normal & + & - & 4 & Duplex, VUR & - \\
\hline 14 & 16 & $\mathbf{F}$ & Raised & - & - & $\begin{array}{c}4 \times 3 \\
\text { Partial }\end{array}$ & - & - \\
\hline
\end{tabular}

\section{Table III Dysplastic cases}

\begin{tabular}{llllllll}
\hline No. & Age & Sex & Blood Pressure & Urinary Infection & Pain & Kidney Length (cm) & Associated Anomalies \\
\hline 15 & 34 & F & Normal & + & - & 8 & Vesico-ureteric reflux \\
16 & 24 & M & Normal & - & - & 8 & 8 \\
17 & 36 & F & Normal & + & - & 8 & Bilharzia \\
18 & 68 & M & Normal & - & - & 9 & Vesico-ureteric reflux \\
19 & 35 & M & Normal & + & - & 8 & Bladder carcinoma \\
20 & 24 & M & Raised & - & - & $6 \cdot 5$ & Pelvi-ureteric obstruction \\
21 & 36 & F & Raised & - & - & 9 & 6 \\
22 & 38 & F & Raised & + & - & 6 & Vesico-ureteric reflux \\
23 & 61 & F & Raised & - & &
\end{tabular}

Table IV Aglomerular scars

or functional abnormality of drainage. However, hypertension was rare; in only two was the blood pressure significantly raised, and in one of these it fell permanently after nephrectomy.

\section{Case 4}

A 54-year-old woman had had recurrent urinary infections for 36 years. Physical examination was negative. Blood pressure was $130 / 80 \mathrm{mmHg}$ and plasma urea $4.8 \mathrm{mmol} / \mathrm{l}$.

An intravenous pyelogram showed a small, poorly functioning right kidney $(7 \mathrm{~cm})$ with generalized narrowing of substance, about $2 \mathrm{~mm}$ thick, and a large hypertrophied left kidney $(16 \mathrm{~cm})$.

A micturating cystogram showed right vesicoureteric reflux and slight dilatation of the ureter.

The kidney measured $5 \times 3 \times 1.5 \mathrm{~cm}$ with irregular depressions on the outer surface and a partially extrarenal pelvis. Most calyces were dilated in relation to depressions, and in these areas the parenchyma was reduced to $0.2 \mathrm{~cm}$ thick. At one end a nodule of normal renal tissue was present.

On microscopical examination thin areas of cortex contain numerous dilated cystic tubules interspersed with dysplastic primitive ducts but no glomeruli. Blood vessels are numerous and hyperplastic. There is slight focal lymphocytic infiltration in the fibrotic interstitial tissue. In the medulla scanty dysplastic ducts are scattered in a loose mesenchyme in which smooth muscle bundles are prominent. Focal calcification is present around dilated collecting ducts but inflammation is scanty and mainly confined to the subepithelial region of the pelvis. The nodule of renal tissue at one pole is essentially normal.

\section{Case 8}

A 25-year-old man had had dull, throbbing, intermittent left loin pain for four years with negative physical and urine examinations. His blood pressure was $140 / 85 \mathrm{mmHg}$ and plasma urea $4.8 \mathrm{mmol} / \mathrm{l}$.

An intravenous pyelogram showed a poorly functioning left kidney $(11 \mathrm{~cm})$ with some pelviureteric junction obstruction and dilatation of the pelvicalycine system, and hypertrophy of the right kidney (16 cm long).

The kidney measured $8 \times 4.5 \times 3 \mathrm{~cm}$ after fixation with several very deep surface depressions beneath which the parenchyma was thinned to $7 \mathrm{~mm}$ and the calyces were clubbed. The tissue was up to $2.5 \mathrm{~cm}$ thick in the prominent surface areas but beneath these there was also dilatation of the calyces. The pelvis was partly extrarenal and up to $5 \mathrm{~cm}$ in diameter, the calyces up to $3 \mathrm{~cm}$ diameter, and the pelvi-ureteric junction was narrow; below this the ureter was normal. 


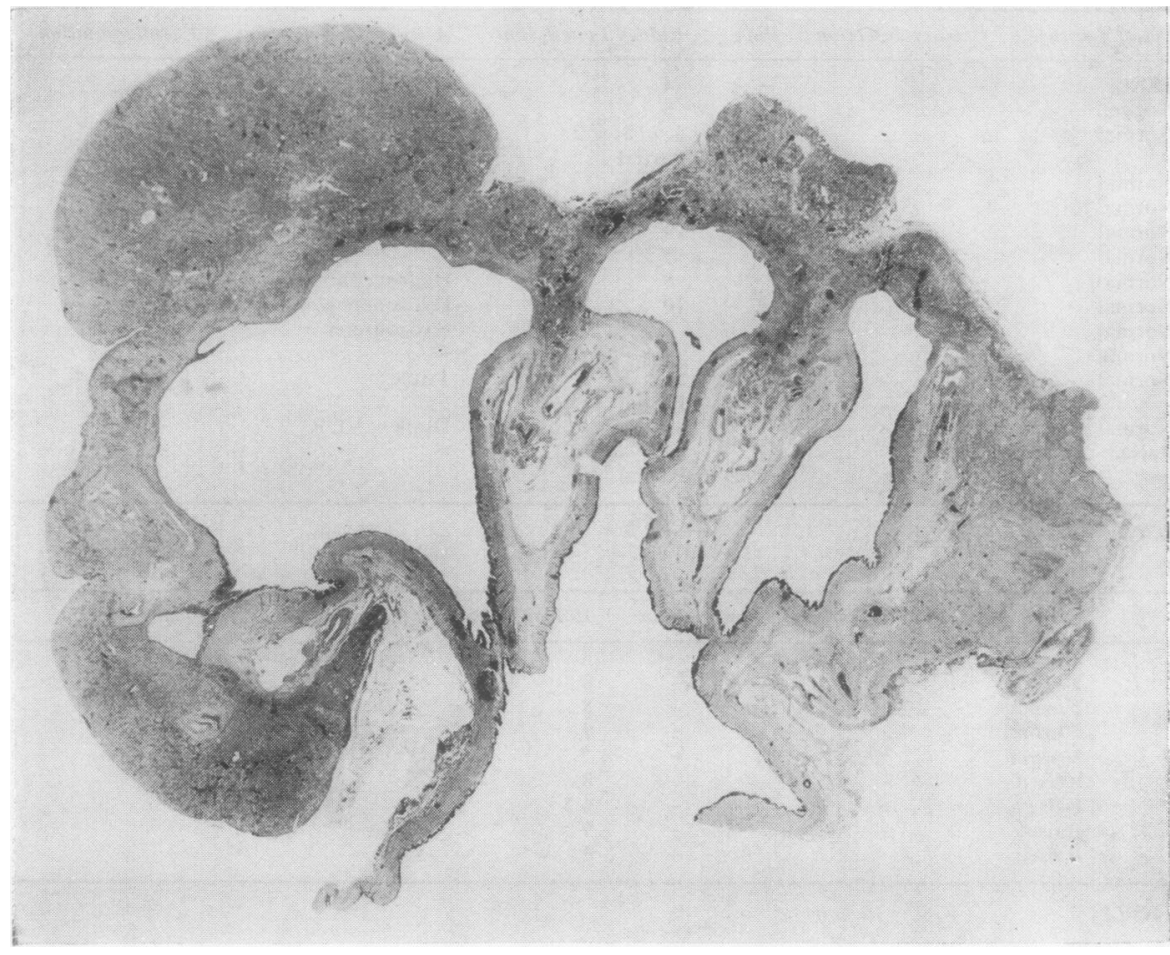

Fig 7 Case 8. Section through whole kidney shows alternation of well developed reniculi and dysplastic areas, and clubbed calyces beneath areas of dysplasia. $H$ and $E$ $\times 2$.

Microscopical examination of a section through the whole kidney (fig 7) shows a sharp alternation of protruding well developed reniculi and smaller dysplastic areas. In the cortex of the latter a few atrophic glomeruli only are present together with scanty dysplastic ducts, some small dilated tubules, islands of closely packed undifferentiated oval mesenchymal cells, and numerous thick-walled arterioles in a fibrous mesenchyme which also contains bundles of smooth muscle. In the medulla the tissue is again a fibromuscular mesenchyme in which there are numerous islands containing a mixture of undifferentiated cells and small primitive tubules (fig 6). There are also a few dysplastic tubules with fibromuscular collars, and collecting ducts are sparse.

In the protruding reniculi the cortex is well formed and normal in most places except for a few scattered groups of oval mesenchymal cells. The outer medulla below is also normal but the inner medulla resembles that of dysplastic areas. Adjacent to normal areas are a few intermediate ones with atrophic tubules and some damaged glomeruli.

This is an unusual case in which the key features are the alternation of normally formed reniculi and dysplastic areas in which undifferentiated blastema is present to a greater degree than in any other example. The hydronephrosis has probably modified the picture to some extent.

\section{Case 13}

A 34-year-old woman had had recurrent urinary infections since childhood. Physical examination was negative. Her blood pressure was $130 / 70 \mathrm{mmHg}$ and plasma urea $5.8 \mathrm{mmol} / \mathrm{l}$.

An intravenous pyelogram showed a small, poorly functioning left kidney $(5 \mathrm{~cm})$ and an hypertrophied right kidney $(15 \mathrm{~cm})$. with some upper pole scarring.

A micturating cystogram showed marked left vesico-ureteric reflux with ureteral dilatation and filling of a small diseased left kidney. There was slight reflux on the right side.

The kidney was $4 \mathrm{~cm}$ long with irregular surface depressions over clubbed calyces opening into a dilated thick-walled pelvis $(3 \mathrm{~cm}$ diameter).

On microscopical examination (fig 8) there is at each end a small area of normal renal tissue. The intervening three-quarters of the kidney is abnormal and thinned. In this area the cortex is devoid of glomeruli, several microcysts are present, usually subcapsular with flattened epithelial lining, and numerous other dilated tubules often containing colloid material. The interstitium contains numerous thick-walled small blood vessels. There are several 


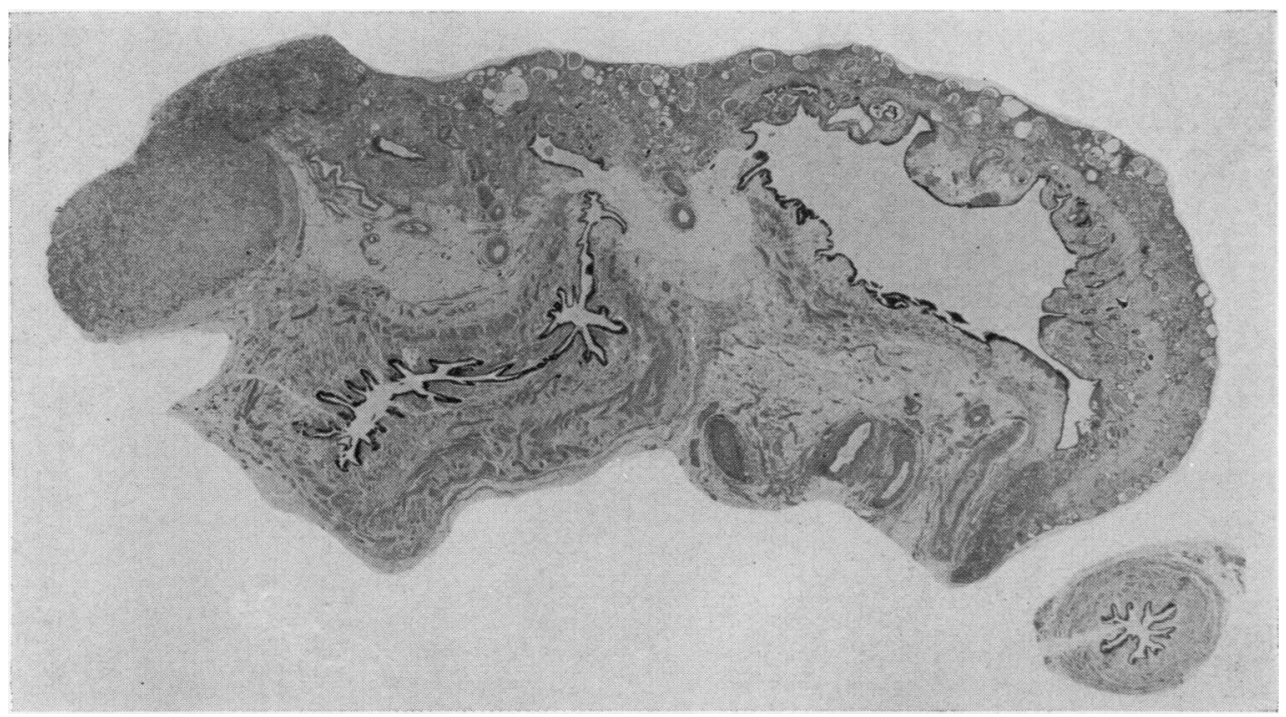

Fig 8 Case 13. Section through whole kidney shows areas of normal tissue near each pole with intervening dysplastic cortex and medulla. $H$ and $E \times 4$.

dysplastic primitive ducts and ductules in the deeper part of the cortex, mostly with atrophic epithelium (fig 4).

The medulla is a zone of loose fibrous tissue containing a few delta-like scattered dysplastic primitive ducts. There is a scanty, mainly subepithelial, chronic inflammatory infiltrate. There is also a focus of three small cysts containing calcified material.

\section{GROUP 2 CHRONIC PYELONEPHRITIS}

This category was used for those examples in which histological and naked-eye criteria of chronic pyelonephritis were satisfied but without dysplasia, stones or hydronephrosis, in all of which chronic inflammation may be a feature. The reason for this was to isolate chronic pyelonephritis from such associations and to compare the isolated cases with the dysplastic group. This group corresponds to the chronic atrophic pyelonephritis of the literature.

The clinical associations are given in table II, and it is worth emphasizing that the incidence of hypertension is greater than in dysplasia. The incidence of vesico-ureteric reflux was about the same as in the dysplastic group but that of abnormalities of drainage and fusion was less.

The separation of these cases of chronic pyelonephritis with aglomerular scars from dysplasia is referred to in the discussion. In this small subgroup of nine there was an abnormality predisposing to long continued infection in five cases, namely, vesico-ureteric reflux in two, and single examples of carcinoma of bladder, pelvi-ureteric obstruction, and Schistosomal cystitis.

\section{Case 18}

A 68-year-old man had had a bladder papilloma excised from the region of the right ureteric orifice 30 years previously. An intravenous pyelogram was normal at that time. Subsequent recurrences were treated by fulguration, and there were occasional episodes of urinary infection. He was admitted with such an attack due to Escherichia coli and complicated by septicaemia. This was satisfactorily treated. His blood pressure was $130 / 90 \mathrm{mmHg}$ and plasma urea $4.5 \mathrm{mmol} / 1$.

An intravenous pyelogram showed a poorly excreting right kidney with a scar overlying a clubbed calyx. The left kidney was hypertrophied $(17 \cdot 5 \mathrm{~cm})$.

Cystoscopy showed a pinhole right ureteric orifice surrounded by firm fibrous tissue. There was no reflux and ureteric catheterization was not possible.

The kidney was $9 \mathrm{~cm}$ long with a $2 \times 3 \mathrm{~cm}$ surface deep scar overlying a clubbed calyx with a smooth lining. The renal parenchyma was $0.2 \mathrm{~cm}$ thick in the scar. Adjacent kidney was normal (fig 9).

On microscopical examination of the scar the cortex contains no normal or abnormal glomeruli but is composed of numerous crowded dilated tubules and thick-walled blood vessels. The tubules are of varying size, lined by flattened cubical epithelium, and most contain eosinophilic colloid 


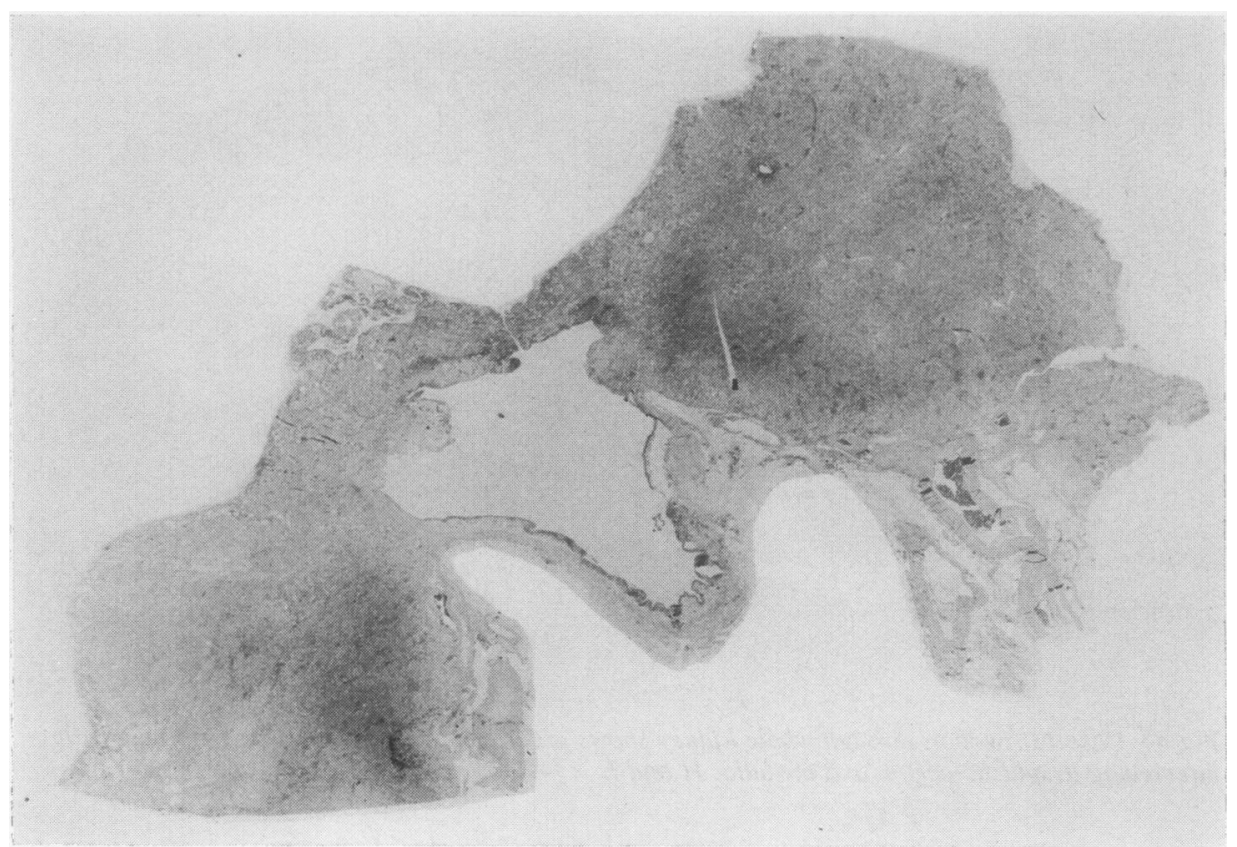

Fig 9 Pyelonephritic scar in which glomeruli were absent from cortex but there were no dysplastic tubules. $H$ and $E \times 3$.

material. There is a small amount of interstitial fibrosis and scanty lymphocytic infiltration.

Deep to this is a zone of thick-walled small arteries overlying an outer medullary zone of fibrosis. The subepithelial zone of the medulla contains a few dilated and atrophic collecting ducts in a scanty, inflamed, oedematous stroma. No dysplastic structures are seen. The adjacent kidney is normal apart from occasional subcapsular foci of dilated tubules. The blood vessels here show minimal elastic hyperplasia.

\section{Discussion}

The recognition of segmental dysplasia as an important cause of renal pathology for which nephrectomy is performed in adolescence and adult life is the significant result of this survey. Total dysplasia is a more obvious but rare lesion in this connection.

The discussion as to whether such cases as those in table II are indeed dysplastic or the result of chronic pyelonephritis alone has been disputed for many years because of the difficulty of distinguishing chronic pyelonephritic scars from segmental dysplasia. The delineation of the latter has been helped by the description of dysplasia in neonates and infants (Ericsson and Ivemark, 1958; Bernstein, 1968; Risdon, 1971). There is now considerable agreement that dysplasia can be segmental and that the key features in its recognition are the presence of primitive collecting ducts with collars of fibromuscular tissue in the abnormal medulla, sometimes with the addition of cartilage. The latter was not seen in the present series. However, it is difficult to conceive of the abnormal ducts occurring as the result of an inflammatory process, particularly when the features of such a process are absent, as was the case in several of the examples in the present series. Case 8 was unusual in that the relics of a primitive blastema were more prominent than the ducts with fibromuscular collars. Another useful diagnostic feature is the presence of tubules with a delta-like configuration, as described by Marshall (1953).

The presence of foci of calcification both within dysplastic tubules and adjacent to them may be helpful in diagnosis. Its significance is not clear as it was not associated with calculi in calyces, pelves or lower urinary tract. This is a calcification in an abnormal tissue rather than a reflection of a general metabolic process. In view of the absence of cartilage in these kidneys compared to infantile examples of dysplasia, the possibility was considered that these were areas of calcified degenerate cartilage. In a few cases the matrix contained abundant acid mucopolysaccharide but cartilage cells could not be 
identified.

The identification of dysplastic cortex is not so clear-cut as medulla. Primitive collecting ducts as seen in the medulla are acceptable but we were less sure of the origin of small abnormal ducts and glomeruli as described by Marshall (1953, 1956). These may be dysplastic but their occurrence in the absence of other features has not been accepted in this series as sufficient for diagnosis. In most of our cases glomeruli were absent from the cortex, but in case 6 a small island of fairly normal cortex with glomeruli was present within an otherwise completely dysplastic kidney, and in cases 1 and 8 hyalinized and partly hyalinized forms were seen. The appearances in the latter two may have been modified by hydronephrosis (see below). Cortical tubules with flattened epithelium and colloid casts were seen frequently and can occur as a result of disease or dysplasia. A cortical interstitial tissue with bands of smooth muscle was thought to be a pointer towards dysplasia.

It is not therefore possible to use the presence or absence of glomeruli as a positive diagnostic criterion of dysplasia. The investigation naturally led to the question whether glomeruli could disappear completely as a result of chronic pyelonephritis. The fact that a few atrophic forms can nearly always be demonstrated in the thin cortex of severe hyd:onephrosis or pyonephrosis if PAS or van Gieson stains are used made us sceptical about this. Furthermore, the literature on pyelonephritis in animals, while suggesting that glomeruli disappear, does not actually illustrate the final absence. However, cases such as 18 (see report) and also 17, in which there was radiological evidence of normal kidneys in early life before a nephrectomy at 37 years, provide strong evidence that the pathological areas in the excised kidneys are scars. In these, glomeruli were absent and a review of the whole series provides an additional seven in which glomeruli were absent and in which dysplastic features were not present. Zollinger (1957) argued that glomeruli can disappear following acute pyelonephritis in early childhood, and Heptinstall (1966) accepts this possibility.

We concluded, therefore, that both segmental dysplasia and aglomerular pyelonephritic scars exist and that they can be separated pathologically although segmental dysplasia may be complicated by chronic inflammation. The cases reported by Reziciner and Batzenschlager (1972) as 'hypoplasie rénale segmentaire aglomérulaire' include insufficient detail in their case reports to determine whether they are all examples of dysplasia as described above, but some appear to be. Throughout the literature the terms hypoplasia and dysplasia are used in a somewhat confusing way. In general, we think dysplasia is more accurate than segmental hypoplasia (Bengtsson and Hood, 1971) because there is an abnormality of development rather than a small but structurally normal kidney.

In considering the cause of the dysplasia, it is necessary to note the high incidence of either abnormalities of drainage or reflux (10 of 14 cases). This is less than the $90 \%$ of anatomical anomalies of the urinary tract in the series of Rubenstein et al (1961) and the $100 \%$ in the series of Risdon (1971). The fact that four of our cases occurred without such a lesion or reflux indicates that it is not an essential factor. It is possible that the same factors that determine the urinary tract malformation are responsible for the dysplastic kidney, and it would appear premature at the present time to suggest that these are environmental rather than genetic as there is no firm evidence of either.

In recent years the importance of intrarenal reflux as a cause of scarring of the kidneys of young children has been raised (Rolleston et al, 1974). It is not proposed to discuss the controversial problem of reflux and pyelonephritis here but it is worth emphasizing that in many of the cases of segmental dysplasia in table II the abnormal areas were in the midzone of the kidney. This contrasts with the scars attributed to intrarenal reflux which tend to be at the poles.

Two clinical associations of segmental dysplasia will be mentioned briefly. Infection was present in six of our 14 cases, and in five of these an anatomical or functional abnormality of drainage was present. It is probable that this predisposed to infection as the obstruction was in no case complete. In case 6 , in which the obstruction was complete, there was no infection. Risdon (1971) has emphasized the absence of infection in cases in which the ureter is atretic or absent and discussed its significance.

Hypertension was present in only two of the cases of dysplasia recorded here. This is much less than that reported by Ekström (1955) and by Bengtsson and Hood (1971), and contrasts with the incidence of hypertension in chronic pyelonephritis discovered at necropsy [usually about $66 \%$ (Heptinstall, 1966)]. In our nephrectomy cases of chronic pyelonephritis hypertension occurred in $16(50 \%)$, and in four (45\%) of those with aglomerular scars. Although the number of cases is insufficient for conclusions to be drawn about the significance of these changes in relation to hypertension, one point deserves further investigation. This is the possibility that congenital segmental absence of glomeruli is less important in the pathogenesis of unilateral renal hypertension than acquired damage even if that leads to their disappearance. 


\section{References}

Bengtsson, C. and Hood, B. (1971). The unilateral small kidney with special reference to the hypoplastic kidney. Int. Urol. Nephrol., 3, 337-351.

Bernstein, J. (1968). Developmental abnormalities of the renal parenchyma-renal hypoplasia and dysplasia. Path. Ann., 3, 213-247.

Bernstein, J. and Meyer, R. (1961). Congenital abnormalities of the urinary system. II: Renal cortical and medullary necrosis. J. Paediat., 59, 657-668.

Ekström, T. (1955). Renal hypoplasia. A clinical study of 179 cases. Acta chir. scand., Suppl. 203.

Ericsson, N. O. and Ivemark, B. I. (1958). Renal dysplasia and pyelonephritis in infants and children. Arch. Path., 66, 255-269.

Gifford, R. W., Jr., McCormack, L. J., and Poutasse, E. F. (1965). The atrophic kidney: its role in hypertension. Mayo Clin. Proc., 40, 834-852.

Heptinstall, R. H. (1966). Pathology of the Kidney. Little, Brown, Boston (1967). J. \& A. Churchill, London.
Marshall, A. G. (1953). The persistence of foetal structures in pyelonephritic kidneys. Brit. J, Surg., 41, 38-50.

Marshall, A. G. (1956). Scars of the renal cortex. J. Path. Bact., 71, 95-109.

Powell, T., Shackman, R., and Johnson, H. D. (1951). Multilocular cysts of the kidney. Brit. J. Urol., 23, 142-152.

Reziciner, S. and Batzenschlager, A. (1972). Hypoplasie rénale segmentaire aglomérulaire. Ann. Urol., 6, 85-91.

Risdon, R. A. (1971). Renal dysplasia. Part I. J. clin. Path., 24, 57-65.

Rolleston, G. L., Maling, T. M. J., and Hodson, C. J. (1974). Intrarenal reflux and the scarred kidney. Arch. Dis. Childh., 49, 531-539.

Rubenstein, M., Meyer, R., and Bernstein, J. (1961). Congenital abnormalities of the urinary system. I. A postmortem survey of developmental anomalies and acquired congenital lesions in a children's hospital. J. Paediat., 58, 356-366.

Zollinger, H. U. (1957). Pathogenese und Folgen einseitiger Zweignieren bei Jugendlichen. Schweiz. med. Wschr., 87, 990-995. 